\section{THU0458 READY OR NOT? CHANGES IN THE CLINICAL PROFILE OF GOUT PATIENTS OVER THE LAST 25 YEARS}

S.P. Chinchilla ${ }^{1,2}$, I. Urionagüena ${ }^{3}$, F. Perez-Ruiz ${ }^{1,2,3} \cdot{ }^{1}$ University of the Basque Country, Bilbao; ${ }^{2}$ Arthritis Research Group, BioCruces Health Research Institute; ${ }^{3}$ Rheumatology Division, Hospital Universitario Cruces, Barakaldo, Spain

Background: The number of publications associated to gout, as well as the prevalence of the disease, has increased in recent years. Gout is a rising cause of hospital admissions and emergency consults. More so in patients with comorbidities, it has even replaced rheumatoid arthritis as the principal rheumatological condition causing admissions (1). Some questions arise in this setting: What are the characteristics of our patients? How have they changed over the past years? Objectives: To analyze possible changes in the epidemiologic, clinical and biochemical profiles of gout patients during a period of 25 years.

Methods: Data was collected from a prospective cohort of gout patients, from a crystal arthritis clinic in a tertiary hospital, with a reference population of half a million inhabitants. A period of 25 years was reviewed, between 1992 and 2016 ( $n=1137$ ), with further division into five quinquennia $(Q)$ for comparison purposes. When entering the cohort, epidemiologic, clinic, laboratory and imaging data are systematically collected. Variables susceptible to change in time were considered: age, gender, gout specific clinical data (articular pattern, presence of tophi), previous admissions due to gout, comorbidities and association with other conditions. Quantitative variables were analyzed with ANOVA and Bonferroni correction; qualitative variables with chi-square test. Inclusion of patients to the cohort was approved by the hospital ethics committee. Results from extreme quinquennia are reported (1stQ: 1992-1996/5thQ 2011-2016 or 2ndQ: 1997-2001/4th: 2006-2010). All results are statistically significant unless stated otherwise.

Results: Differences were observed amongst the periods of five years and age at first visit (1stQ: $54.1 \pm 10.9 / 5$ thQ: $64.6 \pm 13.8$ years); gender (1stQ: $2.6 \% / 5$ thQ: $12.2 \%$ of women, respectively). There were no differences when comparing with years of disease evolution before the first visit.

Initial comorbidities: important differences pertaining the prevalence of cardiovascular disease were observed (2ndQ: 26.3\%/5thQ: $43.2 \%$ ), as well as renal disease (1stQ: $16.7 \% / 5$ thQ: $45.2 \%$ ), hypertension (1stQ: $27.3 \% / 5$ thQ: $75.1 \%$ ) and hyperlipidaemia (1stQ: $50.6 \% / 5$ thQ: $61.2 \%$ ) -although this was not the case for Diabetes Mellitus. There was difference amongst periods and association with acute episodes of calcium pyrophosphate arthritis (1stQ: 3.8\%/5thQ: $5.9 \%$ ).

Initial clinical characteristics: differences were found in presentation with tophi (2ndQ: 23.6\%/4thQ: 40.1\%); polyarticular disease (1stQ: $32.9 \% / 5$ thQ: $41.3 \%$ ); hospital admission on the year prior to inclusion (1stQ: $14.5 \% / 5$ thQ: $24.4 \%$ ); use of diuretics (1stQ: 6.4\%/5thQ: 45.9\%); and uricaemia, the latter with no relevant clinical significance.

Conclusions: The profile of gout patients has notably changed in the past 25 years: we have elder, more complex patients, with higher rates of hospital admissions, with severe forms of disease and important comorbidities. When considering these results, we believe that a substantial proportion of gout patients will require specialized attention in the coming years.

References:

[1] Lim SY, Lu N, Oza A, et al. Trends in Gout and Rheumatoid Arthritis Hospitalizations in the United States, 1993-2011. JAMA. 2016 Jun 7;315(21):2345-7. Disclosure of Interest: S. Chinchilla Grant/research support from: BBKBioCruces Post Fellowship Research Grant 2016-2017, I. Urionagüena: None declared, F. Perez-Ruiz Consultant for: Amgen, Ardea, AstraZeneca, Grünenthal, Menarini, Speakers bureau: AstraZeneca, Grünenthal, Menarini

DOI: 10.1136/annrheumdis-2017-eular.5459

\section{THU0459 EXPLORING DUAL MODULATION OF GLUT9 AND OAT3, AN APICAL AND BASOLATERAL TRANSPORTERS IN PROXIMAL TUBULES AND EXPERIMENTAL MICE}

S.H. Lee, S.B. Kim, D.-S. Oh. The K-herb Research Centre, Korea Institute of Oriental Medicine, Daejeon, Korea, Republic Of

Background: Uric acid homeostasis is a set of the balance in glomerular filtration, tubular secretion, reabsorption, and excretion. In the course of cascade, two kinds play a pivotal role; efflux transporters in apical at renal proximal tubular membrane, uptake ones in basolateral at membrane. The former has been of interest in the targets for uricosuric effects, however, dual modulation of the two could keep uric acid balance in stable ways.

Objectives: The aim of this study was to assess the uptake of seven test articles in the course of the expressions of apical/basolateral transporters in potassium oxonate (PO)-treated kidney epithelial cell lines (Caco-2, MDCK, LLC-PK1) and ICR mice.

Methods: The selected cell lines were treated with potassium oxonate $(0.25$ $\mathrm{mM}$ ) and then modulated by seven test articles, the commercial herbal products (SITK01 through SITK06 and SITT01) at dose range of $0.015-1 \mathrm{mg} / \mathrm{mL}$. To determine efficacious dose range by each test article, three cell lines, Caco-2, MDCK and LLC-PK1 cells were assessed with MTT assay. Forty eight ICR mice were injected intraperitoneally with PO at a dose of 200 and $400 \mathrm{mg} / \mathrm{kg}$ and then blood draws were conducted $0,6,12,24,72$ hours after PO administration. The levels of uric acid and transporters were also measured by ELISA assay and Western blotting analysis in those cell lines.
Results: Treatment of SITK01 through SITK03 and SITT01 at concentration (250 $\mathrm{mg} / \mathrm{mL}$ ) decreased the cell viability. The PO-stimulated kidney epithelial cells with SITK01 through SITK03 treatment increased GLUT9 by 2.5 folds and decreased OAT3 by 1.5 folds (versus controls, $p=0.012$, and $p=0.017$, respectively). In PO-treated mice, uric acid levels were increased through GLUT9 and OAT3 transporters. The results indicated that SITK01, SITK02, and SITK03 showed the potential on uricosuric effects in a dual modulation of apical/basolateral sides of kidney epithelial tubular membranes.

Table 1. Protein expression of transporters in apical and basolateral membranes of proximal tubular epithelial cells and potassium oxonate-treated experimental mice

\begin{tabular}{|c|c|c|c|c|c|c|}
\hline Membrane domain & Functions & Transporters & Caco-2 & MDCK & LLC-PK1 & $\begin{array}{l}\text { Potassium } \\
\text { Oxonate- } \\
\text { treated mice }\end{array}$ \\
\hline Apical & $\begin{array}{l}\text { Palpation of } \\
\text { excretion }\end{array}$ & $\begin{array}{c}\text { SLC22A12 (URAT1) } \\
\text { SLC2A9 (GLUT9) } \\
\text { ABCG2 (BCRP) }\end{array}$ & + & ++ & ++ & $\begin{array}{l}++ \\
++\end{array}$ \\
\hline Basolateral & $\begin{array}{l}\text { Inhibition of } \\
\text { reabsorption }\end{array}$ & $\begin{array}{l}\text { SLC22A6 (OAT1) } \\
\text { SLC22A8 (OAT3) }\end{array}$ & +++ & $\begin{array}{c}+ \\
+++\end{array}$ & $\begin{array}{c}++ \\
+\end{array}$ & ++ \\
\hline
\end{tabular}

Conclusions: The present findings demonstrated that three commercial herbal products showed potentials to reduce hyperuricaemia-induced condition by changing protein expression levels in a transporter-uptake assay. The OAT3 and GLUT9 could be further investigated as the uricosuric group-targets on the bilateral sides at kidney epithelial tubular membranes.

References:

[1] Fromm MF, König J. Transporters and drug-drug interactions: important determinants of drug disposition and effects. 2015 Nature Reviews Drug Discovery $14,543-560$

[2] Giacomini KM, Lawrence Lin, Sook Wah Yee, Richard B. Kim \& Kathleen. SLC transporters as therapeutic targets: emerging opportunities. 2015 Nature Reviews Drug Discovery 14, 543-560.

Acknowledgements: This study was supported by the Traditional Korean Medicine R\&D program funded by the Ministry of Health \& Welfare through the Korea Health Industry Development Institute (KHIDI, Grant \# HI16C0864). The commercial products were donated by the virtue of Kracie Pharma, Ltd. and Tsumura \& Co.

Disclosure of Interest: None declared

DOI: 10.1136/annrheumdis-2017-eular.2816

\section{THU0460 BARRIERS TO GOUT CARE: A SYSTEMATIC REVIEW AND THEMATIC SYNTHESIS OF 120 PROVIDERS AND 480 GOUT PATIENTS FROM QUALITATIVE STUDIES}

S.K. Rai ${ }^{1,2}$, H.K. Choi ${ }^{1,2}$, S. Choi ${ }^{3}$, A. Townsend ${ }^{1,4}$, M.A. De Vera ${ }^{1,5},{ }^{1}$ Arthritis Research Canada, Vancouver, Canada; ${ }^{2}$ Division of Rheumatology, Allergy, and Immunology, Massachusetts General Hospital, Boston, United States; ${ }^{3}$ Faculty of Medicine, University of British Columbia, Vancouver, Canada; ${ }^{4}$ Exeter Medical School, University of Exeter, Exeter, United Kingdom; ${ }^{5}$ Faculty of Pharmaceutical Sciences, University of British Columbia, Vancouver, Canada

Background: Despite gout's well-known pathogenesis and the availability of effective urate-lowering therapy (ULT), management remains poor. However, limited research has sought to improve care among this patient population. An in-depth understanding of provider and patient perspectives on barriers to the delivery of optimal gout care is critical to informing the development of evidence-based interventions to effectively improve disease management and patient outcomes.

Objectives: To systematically review and thematically synthesize qualitative studies to date reporting provider and patient barriers to gout management. Methods: We conducted a mapped search of MEDLINE, EMBASE, Cumulative Index to Nursing and Allied Health Literature, and Social Sciences Citation Index databases and selected qualitative studies reporting provider and patient perspectives on gout management. Thematic synthesis was used to combine the source studies and identify key themes across studies. Two authors independently read and annotated the data and after discussion agreed on an initial coding framework. Concepts were organized into descriptive themes, and the relationships between these descriptive themes were further explored to develop higher-order analytical themes.

Results: Our search strategy retrieved 2,750 articles after the removal of duplicates. After full-text review, 20 studies spanning several geographic settings worldwide (i.e., the US, the UK, New Zealand, Australia, and the Netherlands) met all inclusion criteria and were included in our systematic review. Of these, 16 studies reported gout patient perspectives ( $n=480$ patients), while only 7 studies reported provider perspectives ( $n=120$ providers, including general practitioners, rheumatologists and other specialists, and allied health professionals). Thematic synthesis identified three predominant interlocking analytical themes among providers: (a) knowledge gaps and management approaches, (b) perceptions and beliefs about gout patients, and (c) system barriers to optimal gout care (Table 1). We further identified four predominant themes among gout patients: (a) limited gout knowledge (e.g., the "curable" nature of gout), (b) attitudes toward taking medication, (c) interactions with healthcare providers, and (d) practical barriers to chronic medication use (Table 1). 
Table 1. Illustrative Provider and Patient Quotations from Source Studies

\begin{tabular}{|c|c|c|}
\hline Analytical Theme & Quotation & Reference \\
\hline \multicolumn{3}{|l|}{ Provider Barriers } \\
\hline $\begin{array}{l}\text { Knowledge gaps and } \\
\text { management } \\
\text { approaches }\end{array}$ & $\begin{array}{l}\text { "I think that there is lack of knowledge by both patients and } \\
\text { health professionals. I just thought you just had gout flare ups } \\
\text { and then it just went away, so there is definitely a need for } \\
\text { education and better training." }\end{array}$ & $\begin{array}{l}\text { Spencer et } \\
\text { al. }\end{array}$ \\
\hline $\begin{array}{l}\text { Perceptions and } \\
\text { beliefs about gout } \\
\text { patients }\end{array}$ & $\begin{array}{l}\text { "Adherence to uric acid-lowering therapy is not a problem in } \\
\text { patients with gout, since they are well aware of the fact they will } \\
\text { get new gout attacks if they do not take their medication." }\end{array}$ & $\begin{array}{l}\text { Spaetgens } \\
\text { et al. }\end{array}$ \\
\hline $\begin{array}{l}\text { System barriers to } \\
\text { optimal gout care }\end{array}$ & $\begin{array}{l}\text { "It's another thing, too, the time issue. Cause if you're really, } \\
\text { really busy, you don't spend time to talk to the patient, you don't } \\
\text { have time, if we're busy." }\end{array}$ & $\begin{array}{l}\text { Humphrey } \\
\text { et al. }\end{array}$ \\
\hline \multicolumn{3}{|l|}{ Patient Barriers } \\
\hline $\begin{array}{l}\text { Limited gout } \\
\text { knowledge }\end{array}$ & $\begin{array}{l}\text { "I think I have accepted the fact that there is no cure. It is up to } \\
\text { me just to minimize it, I think. I don't think there is any cure } \\
\text { because I haven't talked to anybody who has had it and say } \\
\text { they don't get it anymore. Is that possible?" }\end{array}$ & $\begin{array}{l}\text { Lindsay et } \\
\text { al. }\end{array}$ \\
\hline $\begin{array}{l}\text { Attitudes toward taking } \\
\text { medication }\end{array}$ & $\begin{array}{l}\text { "So I know gout's never going to kill me, right. So I don't want to } \\
\text { be taking - I don't want to be rattling around full of tablets all the } \\
\text { time". }\end{array}$ & $\begin{array}{l}\text { Richardson } \\
\text { et al. }\end{array}$ \\
\hline $\begin{array}{l}\text { Interactions with } \\
\text { healthcare providers }\end{array}$ & $\begin{array}{l}\text { "I don't think they gave you enough. It kind of wasn't even the } \\
\text { basics. There were no follow-ups or anything and I was going } \\
\text { regularly. There must have been time in there. I didn't know } \\
\text { about uric acid levels or what I should aim for. In my mind, I } \\
\text { never had it explained." }\end{array}$ & $\begin{array}{l}\text { Te Karu et } \\
\text { al. }\end{array}$ \\
\hline $\begin{array}{l}\text { Practical barriers to } \\
\text { chronic medication us }\end{array}$ & $\begin{array}{l}\text { "I'm frequently too busy with school pressures to worry about } \\
\text { taking medication regularly." }\end{array}$ & Katz et al. \\
\hline
\end{tabular}

Conclusions: Our thematic synthesis identified several barriers to gout care, particularly knowledge gaps among both providers and patients as well as implementation barriers to the provision of optimal care. Knowledge translation initiatives emphasizing the "curable" nature of gout targeting both providers and patients as well as strategies to reduce system barriers and support regular medication use are urgently needed to improve gout care.

Acknowledgements: This study was supported in part by a grant from the Canadian Institutes of Health Research (PCS 146388). We wish to thank the Arthritis Patient Advisory Board of Arthritis Research Canada for providing their consumer input into this project.

Disclosure of Interest: None declared

DOI: 10.1136/annrheumdis-2017-eular.4298

\section{THU0461 ACCURACY OF HUMASENS-PLUS POINT-OF-CARE URIC ACID METER USING CAPILLARY BLOOD OBTAINED BY FINGERTIP PUNCTURE}

S. Fabre $^{1}$, P. Clerson ${ }^{2}$, J.-M. Launay ${ }^{3}$, J.-F. Gautier ${ }^{4}$, T. Vidal-Trecan ${ }^{4}$, J.-P. Riveline ${ }^{4}$, A. Platt ${ }^{5}$, A. Abrahamsson 6 , J.N. Miner ${ }^{7}$, G. Hughes ${ }^{5}$,' P. Richette ${ }^{1}$, T. Bardin ${ }^{1} .{ }^{1}$ Rheumatology department, Hôpital Lariboisière, Paris; ${ }^{2}$ Soladis Clinical Studies, Roubaix; ${ }^{3}$ Biochemistry department; ${ }^{4}$ Diabetology department, Hôpital Lariboisière, Paris, France; ${ }^{5}$ Personalised Healthcare Unit, AstraZeneca, Cambridge, United Kingdom; ${ }^{6}$ Personalised Healthcare Unit, AstraZeneca, Mölndal, Sweden; ${ }^{7}$ Research and development, Ardea Biosciences Inc., San Diego, CA, United States

Background: A key factor in the success of gout management is the long-term lowering of uricemia below predetermined targets (300 or $360 \mu \mathrm{mol} / \mathrm{l})$. Monitoring of uricemia in gout patients is therefore important, and is presently done in the laboratory on plasma samples obtained after venous puncture. An accurate uric acid (UA) meter allowing rapid testing by the health care professionals and self-measurement by the patient should improve management of gout.

Objectives: This study aimed to assess the reliability of immediate UA measurement in capillary blood samples obtained from fingertip puncture using the HumaSens $^{\text {Plus }}$ point-of-care meter (meter) compared with that of a standard laboratory assay (lab).

Methods: Capillary UA levels were measured from 236 consenting diabetic patients using the commercially available HumaSens $s^{\text {Plus }}$ UA meter (European Conformity marked and approved for EU market use). Each patient also had a plasma UA measurement in the biochemistry laboratory using an uricase automated colorimetric assay. Since the UA meter has a dynamic range of 180 $1190 \mu \mathrm{mol} / \mathrm{l}$, when the values were out-ranged (meter reading LO or $\mathrm{HI}$ ), they were individually compared to corresponding plasma measurements. Agreement between capillary and plasma UA levels was assessed by Intraclass Correlation Coefficient (ICC) and Bland-Altman graphic representation. Best capillary UA threshold for detection of hyperuricemia (plasma UA $>360 \mu \mathrm{mol} / \mathrm{l}$ ) was determined from a ROC curve, relationship between methods were identified by regression. Impact of potential confounding factors (biological parameters/treatments) was searched. A total of 206 paired measurements were required for estimation of an ICC of 0.80 with a precision of 0.10 at alpha risk of $0.05 \%$. To better understand discrepancies between meter and lab, results were compared to reference plasma UA measurements by liquid chromatography-mass spectrometry (LC-MS) in a subgroup of 77 patients who gave complementary consent.

Results: Fourteen capillary samples were read LO by the meter: 11 were confirmed by lab to be below $180 \mu \mathrm{mol} / \mathrm{l}$ and 3 were above $(189,206$ and $428 \mu \mathrm{mol} / \mathrm{l})$. Two capillary samples were read $\mathrm{HI}$ and were measured at 303 and $213 \mu \mathrm{mol} / \mathrm{l}$ by lab. In the remaining 222 samples with meter and lab values, ICC was 0.90 [0.87-0.92] and Bland-Altman curve showed acceptable agreement over all the tested values. Best meter threshold for detection of hyperuricemia by the HumaSens ${ }^{\text {Plus }}$ meter was $330 \mu \mathrm{mol} / /$ (sensitivity 0.89 , specificity 0.89 , area under the ROC curve 0.95). Based on regression, plasma uricase of
$360 \mu \mathrm{mol} / \mathrm{l}$ corresponded to $343 \mu \mathrm{mol} / \mathrm{l}$. Among the biological parameters tested, only hematocrit impacted capillary uric acid measurements, however negligibly. No medication appeared to significantly affect test results. Plasma uricase measurements were better correlated to LC-MS measurements ( $r=0.98[0.96-$ $0.99])$ than capillary measurements $(r=0.84[0.75-0.90])$.

Conclusions: Results of the HumaSens ${ }^{\text {Plus }}$ meter were reasonably comparable to those of the laboratory assay. It is easy to use and may be useful in clinic and in epidemiologic studies.

Disclosure of Interest: None declared

DOI: 10.1136/annrheumdis-2017-eular.2787

\section{THU0462 MORTALITY IN PATIENTS WITH GOUT: A SYSTEMATIC REVIEW}

S. Mitchell ${ }^{1}$, H. Liedgens ${ }^{2}$, E. Johannes ${ }^{3} \cdot{ }^{1}$ Decision Resources Group, Bicester, United Kingdom; ${ }^{2}$ Head Health Economics and Outcomes Research Market Access, SBU Europe; ${ }^{3} \mathrm{Head}$ Market Access Europe, Grünenthal GmbH, Aachen, Germany

Background: Gout is a chronic, progressive, inflammatory disease characterised by elevated serum uric acid (sUA) levels (1). In Europe the prevalence of gout ranges from $0.9-2.5 \%$, and is increasing (2). Published data indicate that gout is an independent risk factor for both all-cause and cardiovascular (CV)-related mortality $(3,4)$.

Objectives: To conduct a systematic review to identify studies reporting the association between gout and mortality (all-cause and CV-related).

Methods: Relevant publications were identified by interrogating electronic databases; Medline \& MEDLINE In-Process, EMBASE and the Cochrane Library (accessed 3 May 2016). Eligibility criteria included adult patients with a definitive diagnosis of acute/chronic gout (self-reported/physician diagnosed), with no restriction on publication date, study design or geography.

Results: Nineteen studies met the pre-defined inclusion criteria and were reviewed. The studies were conducted in: the US $(n=8)$; Taiwan $(n=5)$; Canada $(n=3)$; Spain $(n=1)$; Singapore $(n=1)$; and the UK $(n=1)$. In addition to patients having a diagnosis of acute/chronic gout, 6 of the 19 studies were conducted in the following patient subgroups: renal transplant $(n=1)$; chronic kidney disease $(n=2)$; patients with a recent acute myocardial infraction $(n=2)$; and patients with heart failure $(n=1)$. There were several consistent finding across the 19 studies: (i) gout was associated with an increase in both all-cause mortality (reported hazard ratios [HR] ranged from 1.13 to 2.37 ) and CV-related mortality (reported HR ranged from 1.10 to 3.88 ) compared with patients without gout; (ii) the increased risk in all-cause mortality was primarily driven by an increase in CV-related mortality; (iii) the increased mortality risk was higher in females than males. One study reported that the presence of tophi was independently associated with a higher risk of all-cause mortality. Notably one study reported that patients who received urate-lowering therapy (ULT) have a statistically significant lower all-cause mortality and CV-related mortality risk relative to patients who do not receive ULT.

Conclusions: This systematic review confirms that gout is associated with an increased risk of all-cause and CV-related mortality; this was consistently reported across the eligible studies. The findings highlight the risk associated with gout and emphasise the need for appropriate treatment of this curable disease.

\section{References:}

[1] Keenan R, et al. Etiology and pathogenesis of hyperuricemia and gout. Kelley's textbook of rheumatology. Elsevier Saunders. 2013:94:1533-53.

[2] Richette P, et al. 2016 updated EULAR evidence-based recommendations for the management of gout. Ann Rheum Dis. 2016:annrheumdis-2016-209707.

[3] Lottmann K, et al. Association between gout and all-cause as well as cardiovascular mortality: a systematic review. Curr Rheumatol Rep. 2012;14(2):195-203. [4] Clarson L, et al. Increased cardiovascular mortality associated with gout: a systematic review and meta-analysis. Eur J Prev Cardiol. 2015;22(2):335-43. Disclosure of Interest: S. Mitchell: None declared, H. Liedgens Employee of: Grünenthal GmbH, E. Johannes Employee of: Grünenthal GmbH DOI: 10.1136/annrheumdis-2017-eular.6062

\section{THU0463 EPIDEMIOLOGY OF GOUT AND HYPERURICEMIA IN NEW CALEDONIA}

$\mathrm{T}_{\text {T. Bardin }}{ }^{1}$, E. Magnat ${ }^{2}$, P. Clerson ${ }^{3}$, P. Richette ${ }^{4}$, B. Rouchon ${ }^{2} .{ }^{1}$ Rheumatology, Hôpital lariboisière, Paris, France; ${ }^{2}$ Agence Sanitaire et Sociale, Nouméa, New Caledonia; ${ }^{3}$ Soladis Clinical Studies, Roubaix; ${ }^{4}$ Rheumatolofy, Hôpital Lariboisière, Paris, France

Background: New Caledonia is a Pacific island of 270.000 inhabitants with mixed ethnicities, including Melanesians (39.1\%) and Polynesians (10.2\%) and people from European ancestry (27.2\%).

Objectives: To determine the prevalence of gout and hyperuricemia in the various ethnicities and to characterize associated factors.

Methods: A 3-degree random sample of the population aged 18 to 60 years old was redressed according to the 2014 New Caledonia census. Face-to-face interviews were performed by trained nurses who used a predefined questionnaire along with planned physical measurements. All participants underwent capillary measurement of creatinine level (StatSensor) and all men and only women older 